\title{
O PROCESSO DE INTERNACIONALIZAÇÃO E OS ASPECTOS SOCIOAMBIENTAIS: O CASO EMBRAER
}

\author{
Internationalization and sustainability: the Brazilian \\ Embraer case study
}

\author{
André Coimbra Félix Cardoso ${ }^{1}$ \\ Annelise Vendramini da Silva Caridade ${ }^{2}$ \\ Flavio Hourneaux Junior ${ }^{3}$ \\ Isak Kruglianskas ${ }^{4}$
}

\begin{abstract}
Resumo
O objetivo deste trabalho é colaborar para que se compreenda se a capacidade de uma organização competir em um mercado internacional pode ser influenciada por questões relacionadas aos aspectos socioambientais que a envolvem, com base nos diferentes contextos em que esta passa a operar. O estudo, de caráter exploratório e descritivo, trata da análise do processo de internacionalização da Embraer, e pautou-se na estratégia de um estudo de caso único e, como meio de coleta de dados, foi escolhida a entrevista pessoal em profundidade, além de utilização de dados de fontes secundárias. O ponto de destaque como resultado é a necessidade da indústria de aviação se reestruturar sob um novo enfoque, que valorize as variáveis sociais e ambientais, sob pena de sua própria sobrevivência em longo prazo.
\end{abstract}

Palavras-chave: Internacionalização; Gestão Socioambiental; Sustentabilidade.

\footnotetext{
${ }^{1}$ Mestre em Administração, Faculdade de Economia, Administração e Contabilidade da Universidade de São Paulo (FEA-USP), doutorando, professor e consultor em Administração, Av. Luciano Gualberto, 908, São Paulo, SP, Brasil 05508-010. E-mail: ancfelix@uol.com.br

${ }^{2}$ Mestre em Administração, Faculdade de Economia, Administração e Contabilidade da Universidade de São Paulo (FEA-USP), doutoranda, professora e consultora em Administração, Av. Luciano Gualberto, 908, São Paulo, SP, Brasil - 05508-010. E-mail:anne_vendramini@yahoo.com.br

${ }^{3}$ Mestre em Administração, Faculdade de Economia, Administração e Contabilidade da Universidade de São Paulo (FEA-USP), doutorando, professor e consultor em Administração, Av. Luciano Gualberto, 908, São Paulo, SP, Brasil -05508-010. E-mail: flaviohjr@usp.br

${ }^{4}$ Doutor em Administração, Faculdade de Economia, Administração e Contabilidade da Universidade de São Paulo (FEA-USP), professor e consultor em administração, Av. Luciano Gualberto, 908, São Paulo, SP, Brasil - 05508-010.Email: ikruglia@usp.br
} 


\begin{abstract}
This article aims at understanding in what ways sustainability issues can affect the dynamics of an internationalization process, particularly in the aviation industry. This paper presents and discusses the case of EMBRAER, the largest Brazilian aircraft manufacturer in the aeronautical and defense markets; this research is both exploratory and descriptive and it follows the case study method. Data was gathered through a personal interview and secondary sources.
\end{abstract}

Keywords: Internationalization; Social and Environmental Management; Sustainability.

\title{
1 Introdução
}

As sociedades mundiais têm demonstrado apurado senso crítico em relação às atividades das empresas, tanto pelos efeitos negativos que causam no ambiente natural como pelos impactos nas comunidades em que atuam. Desde a década de 1960, o debate sobre a relação entre seres humanos (e em especial o papel das empresas), a sociedade e o meio ambiente vem ganhando dimensões sempre maiores. Desde então, têm surgido Organizações Não-Governamentais (ONG's) com ações globais em defesa do meio ambiente (como Greenpeace, WWF e TNS); diversas conferências internacionais em defesa do ambiente natural (como Estocolmo, Brundtland, Rio 92); assinatura e ratificação de pactos globais (como Protocolo de Kyoto, Global Compact e os Objetivos do Milênio), criação de selos de certificação ambiental (como o Blue Angel e o FSC), criação dos índices de sustentabilidade em diferentes mercados (como Estados Unidos, Europa, África do Sul, Austrália e Brasil), acordo entre bancos para concessão de crédito baseado também em análises socioambientais (Equator Principles) e diversas leis, restringindo as atividades empresariais em razão de preocupações socioambientais. As fontes de pressão agindo sobre as organizações para que incluam as variáveis socioambientais na formulação e gestão estratégica são diversas e ganham escala global.

Com base nesse contexto, o objetivo deste estudo de caso é explorar em que medida os aspectos da gestão estratégica para a sustentabilidade fazem parte da estratégia e como influenciam o forte processo de internacionalização de uma organização brasileira, a Embraer. A Embraer é uma empresa com grande presença internacional, de tecnologia vanguardista e alta competitividade no cenário internacional, produzindo e comercializando aeronaves no exterior, sendo seus fornecedores e parceiros também internacionais. Seu mercado é altamente competitivo, tendo como principais concorrentes a Bombardier (Canadá), Boeing (Estados Unidos) e Air Bus (França). Dessa forma, a Embraer está fortemente exposta às demandas internacionais por práticas de gestão modernas e competitivas. Procurou-se, portanto, conhecer em que medida aspectos da sustentabilidade fazem parte da estratégia da Embraer. Para dar base a essa argumentação, são também levantados, no artigo, conceitos sobre: (a) internacionalização de empresas; (b) aspectos socioambientais e sustentabilidade; e (c) a influência desses aspectos nas estratégias e ações empresariais. Este trabalho, de caráter exploratório e descritivo, pautouse na estratégia de estudo de caso, com a análise de um de caso único e, como meio de coleta de dados, foi escolhida a entrevista pessoal em profundidade, além de utilização de fontes de dados secundários (relatórios anuais, análise de conteúdo de documentos preparados pela empresa e disponíveis em seu sítio). 


\section{Metodologia}

O presente estudo apresenta enfoques tanto exploratórios como descritivos. No entender de Selltiz et al.(1974, p. 59), o estudo exploratório tem como motivação "familiarizarse com um fenômeno ou conseguir nova compreensão deste, para poder formular um problema mais preciso de pesquisa ou criar novas hipóteses". Para Mattar (1996), a pesquisa exploratória pode utilizar vários métodos, como levantamento de dados em fontes secundárias, estudos de casos selecionados e observação informal. O segundo tipo de estudo relacionado anteriormente, o descritivo, tem como foco central o desejo de "conhecer a comunidade, seus traços característicos, suas gentes, seus problemas, suas escolas, seus professores, sua educação, sua preparação para o trabalho, seus valores" (TRIVIÑOS, 1987, p. 110). Triviños (1987, p. 110) afirma ainda que "os estudos descritivos exigem do pesquisador uma série de informações sobre o que deseja pesquisar" e, a partir daí, "descrever 'com exatidão' os fatos e fenômenos de determinada realidade", com a intenção de aprofundar a descrição de determinada realidade.

O método de pesquisa utilizado neste artigo foi o estudo de caso. Tanto Mattar (1996) como Triviños (1987) defendem o estudo de caso como importante ferramenta. Yin (2001, p. 32-33) define este método como "uma investigação empírica que investiga um fenômeno contemporâneo dentro de seu contexto de vida real, especialmente quando os limites entre o fenômeno e o contexto não são claramente definidos". Ademais, o estudo de caso parece ser a melhor estratégia a ser adotada porque os objetivos desta pesquisa vão ao encontro da essência de um estudo de caso, que é a de tentar "esclarecer uma decisão ou um conjunto de decisões: o motivo pelo qual foram tomadas, como foram implementadas e com quais resultados" (SCHRAMM apud YIN, 2001, p. 31).

Para Yin (2001), o método do estudo de casos é adequado para responder a questões do tipo "como" e "por que", que são explicativas e tratam de relações operacionais que ocorram ao longo do tempo mais do que freqüências ou incidências. O método é útil quando um fenômeno é amplo e complexo, e o corpo de conhecimentos existente é insuficiente para permitir a proposição de questões causais ou quando um fenômeno não pode ser estudado fora do contexto no qual ele naturalmente ocorre, que são as principais características do problema investigado neste trabalho. Assim, este trabalho pautou-se na estratégia de estudo de caso único. O método de coleta de dados escolhido foi a entrevista pessoal em profundidade, com um roteiro semi-estruturado, dirigida ao gerente responsável pela área de Infra-estrutura, Meio Ambiente e Segurança no Trabalho da empresa.

\section{Revisão da literatura}

\subsection{Principais conceitos sobre internacionalização}

O processo de internacionalização das empresas líderes de países desenvolvidos começou há bastante tempo. A novidade do tema encontra-se no movimento das empresas de países recém-industrializados que passaram a competir no mercado global, com a instalação de unidades produtivas em distintos países.

Entende-se por empresa multinacional aquela empresa: (i) com entidades em dois ou mais países; (ii) operando sob um sistema de tomada de decisão que permite políticas coerentes e uma estratégia comum através de um ou mais centros de tomada de decisão; e (iii) na qual as entidades estão relacionadas de tal maneira, seja por uma relação de propriedade seja por outra forma, que uma ou mais delas podem ser capazes de exercer uma influência 
significativa sobre as atividades das demais e, em particular, compartilhar conhecimento, recursos e responsabilidades com os outros (BARTLETT; GHOSHAL, 1998). Os tipos de estratégias de internacionalização podem ser definidos de acordo com o Quadro 1.

\begin{tabular}{|l|l|}
\hline Tipo & Capacidades estratégicas-chave \\
\hline $\begin{array}{l}\text { Multinacional ou } \\
\text { Multidoméstica (Porter, } \\
1986)\end{array}$ & $\begin{array}{l}\text { Constrói forte presença local por meio da sensibilidade e capacidade de resposta às } \\
\text { peculiaridades nacionais }\end{array}$ \\
\hline Global & Constrói vantagens de custos por meio de operações centralizadas de escala global \\
\hline Internacional & $\begin{array}{l}\text { Explora o conhecimento e capacidades da matriz por meio da difusão e adaptação } \\
\text { em âmbito global. }\end{array}$ \\
\hline
\end{tabular}

Fonte: Bartlett e Ghoshal (1998, p. 18).

Quadro 1 - Tipos de estratégias de internacionalização.

Em seu estudo, abrangendo empresas americanas, européias e japonesas, Bartlett e Ghoshal (1998) destacam três tipos de multinacionais: empresas com elevado grau de independência (multidomésticas); empresas que se desenvolveram impulsionadas pela necessidade de eficiência global e cujas decisões operacionais e estratégicas são centralizadas (globais) e empresas cuja matriz mantém influência e controle considerável - menor que a global e com menor independência e autonomia que a multinacional (internacionais).

De acordo com Dunning (1999), os principais motivos que levam uma empresa a se internacionalizar eram a disponibilidade de recursos naturais, escassos nos países de origem; a existência de mão-de-obra barata, permitindo o barateamento da produção a custos tão baixos que compensassem os custos adicionais de transporte para outros mercados; e a atratividade dos mercados locais. A partir das décadas de 1970 e de 1980, o contexto passou a mudar significativamente, trazendo novos contornos a essa questão. Os elementos-chave do crescimento econômico contemporâneo estão cada vez mais alojados nos sistemas de empresas transnacionais. Nesse sentido, os governos locais, que no passado estabeleciam normas para a entrada do capital estrangeiro e o funcionamento das empresas multinacionais, estão profundamente preocupados em atrair os investimentos estrangeiros através da criação de uma infra-estrutura local que potencialize a competitividade das subsidiárias instaladas visando à competição global.

De forma geral, os responsáveis pelas estratégias de internacionalização devem estar atentos "aos indicadores econômicos internacionais, aos governos nacionais, às suas estruturas legais, aos concorrentes, aos fornecedores, às tecnologias, à geografia e aos mercados locais" (MORAN; HARRIS; STRIPP; 1996, p. 59).

\subsection{O processo de internacionalização das empresas brasileiras}

Na corrida pelos acessos aos mercados mundiais, a posição ocupada pelo Brasil pode ser considerada ainda extremamente tímida quando comparada à de outros países desenvolvidos ou em desenvolvimento, ocupando a $47^{a}$ p posição entre os 49 países pesquisados com relação ao volume do comércio internacional (FUNDAÇÃO DOM CABRAL, 2002).

Há evidências de que o aumento da competitividade das empresas é influenciado positivamentepelasinovaçõestecnológicasquesãoresultantesdoprocessodeinternacionalização. A abertura de mercados externos geraria maior potencial de expansão e de crescimento da empresa e também a própria internacionalização geraria mecanismos de retroalimentação da sua capacitação tecnológica. Existem evidências, ainda, de que as empresas brasileiras 
internacionalizam-se com o objetivo de buscar informação para realizar inovação tecnológica. Esse tipo de internacionalização afeta positivamente o desempenho exportador das empresas (ARBIX, SALERNO e DE NEGRI, 2005).

Ao discutir as características das empresas de capital brasileiro internacionalizadas Arbix, Salerno e De Negri (2005) caracterizam as empresas em três grupos: as empresas com investimentos diretos no exterior - empresas de propriedade de capital majoritariamente brasileiro (mais de 50\%) com ID; empresas brasileiras sem ID - empresas de propriedade de capital majoritariamente brasileiro (mais de 50\%) sem ID; e firmas transnacionais - empresas de capital majoritariamente estrangeiro (mais de 50\%) que atuam na indústria brasileira.

O Quadro 2 apresenta, de forma resumida, os principais motivos e as principais barreiras encontradas pelas empresas brasileiras, de acordo com uma pesquisa realizada pela Fundação Dom Cabral (2002).

\begin{tabular}{|l|l|}
\hline Motivos & Barreiras \\
\hline $\begin{array}{l}\text { busca de economia de escala - marcante } \\
\text { para os produtores intermediários e os } \\
\text { produtores de bens finais -; varia de acordo } \\
\text { com o porte das empresas; }\end{array}$ & $\begin{array}{l}\text { barreiras internas/organizacionais que dizem respeito à } \\
\text { adequação das capacidades e dos recursos das empresas } \\
\text { para atuar em mercados internacionais; }\end{array}$ \\
\hline $\begin{array}{l}\text { desenvolvimento de competências para } \\
\text { atuar em mercados internacionais - mais } \\
\text { necessário quanto menor o porte da } \\
\text { empresa; }\end{array}$ & $\begin{array}{l}\text { barreiras situadas no ambiente competitivo brasileiro, } \\
\text { elacionadas à adequação da infra-estrutura econômica } \\
\text { características culturais; }\end{array}$ \\
\hline $\begin{array}{l}\text { exploração das vantagens de localização no atitudes e e } \\
\text { Brasil; }\end{array}$ & $\begin{array}{l}\text { barreiras situadas nos mercados de destino, também de } \\
\text { natureza econômica, político-institucional e cultural. }\end{array}$ \\
\hline saturação do mercado brasileiro. & \\
\hline
\end{tabular}

Fonte: adaptado de Fundação Dom Cabral (2002)

Quadro 2 - Motivos e barreiras para a internacionalização das empresas brasileiras.

A estratégia de internacionalização de empresas brasileiras passa, assim, por várias modalidades, incluindo "associação com empresas estrangeiras, visando a novos mercados e ao acesso ao capital mais barato" (SILVA, 2003, p. 152), como é o caso da Embraer, que é o objeto de estudo deste trabalho.

\subsection{Principais conceitos sobre sustentabilidade}

O debate sobre a questão da sustentabilidade tem origem com o conceito original de Desenvolvimento Sustentável, proposto pela Comissão Mundial do Desenvolvimento e Meio Ambiente em 1987 - chamada de Comissão Brundtland - que considera tecnicamente viável prover necessidades mínimas para o dobro da população mundial, de forma sustentável e sem degradação continuada dos ecossistemas globais, a fim de "atender às necessidades da geração presente sem comprometer a habilidade das gerações futuras de atender suas próprias necessidades" (AMARAL e LA ROVERE, 2003). Desde então, vários estudos e ferramentas vêm sendo desenvolvidos. Eles determinam a conduta das organizações que desejam caminhar nessa rota para o desenvolvimento sustentável.

A partir das discussões da Comissão Brundtland, são estabelecidos os chamados objetivos tríplices (Triple Bottom Line), que consideram os três aspectos que seriam essenciais para o desenvolvimento sustentável: 
- econômico: um sistema economicamente sustentável deve ser capaz de produzir produtos e serviços continuamente, sem causar problemas de ordem fiscal ou financeira nos diversos setores produtivos;

- social: um sistema socialmente sustentável obtém justiça na distribuição de renda e oportunidades, com serviços sociais, principalmente saúde e educação, e igualdade de tratamento para todos os seus membros;

- ambiental: um sistema ambientalmente sustentável não compromete as bases de recursos, renováveis ou não-renováveis, utilizando-os parcimoniosamente, além de procurar manter a biodiversidade, a estabilidade da atmosfera e as demais funções do ecossistema (HARRIS et al., 2001, p. xxix).

Assim, um conjunto cada vez mais significativo de normas e leis referentes à questão ambiental passa a tornar mais densa a legislação ambiental e, conseqüentemente, mais rígidos a pressão e o regulamento sobre as atividades empresariais. As empresas começaram também a se preocupar com a quantificação dos recursos consumidos para evitar ou minimizar os impactos de suas atividades sobre o meio ambiente, esboçando sistemas de contabilidade ambiental para gerenciar seus ativos (bens e direitos reservados para a recuperação, a preservação, a proteção e o controle de meio ambiente) e passivos (gastos despendidos com a prevenção ou a correção de problemas de natureza ambiental) ambientais (SCHOEMAKER e SCHOEMAKER, 1995). Tais sistemas podem ter suas atuações em seis esferas distintas (BENNETTT e JAMES, 1998): a contabilidade de energia e materiais, o gerenciamento financeiro de questões relacionadas ao meio-ambiente, a avaliação de ciclo de vida dos produtos, a avaliação dos custos e conseqüências desses ciclos de vida, a avaliação do impacto ambiental e, por fim, a avaliação do custo das externalidades, dos danos e benefícios ambientais causados pelas atividades das empresas.

\subsection{A sustentabilidade e sua influência nos novos modelos de gestão das empresas}

Muitas estratégias competitivas têm sido desenvolvidas a partir das teorias de desenvolvimento sustentável. Entretanto, poucas delas focam a inovação dos projetos, um dos mais importantes elementos para a sua implementação. E, além disso, torna-se necessário considerar a necessidade de alinhamento das estratégias competitivas com as três dimensões do desenvolvimento sustentável: os aspectos econômicos, sociais e ambientais. No entender de Hunt e Auster (1990), as empresas se encontram em diferentes estágios de desenvolvimento de gestão socioambiental:

- de um extremo de perfil reativo, em que inexiste um programa do trato ambiental ou (se houver) o orçamento é tão tênue que torna impotente qualquer ação, expondo as empresas a riscos diversos, tais como multas ambientais e publicidade negativa, entre outras;

- ao outro, pró-ativo, em que são desenvolvidos, em nível corporativo, programas preventivos, treinamento de colaboradores, monitoramentos ambientais e outras práticas.

A partir daí, observa-se a discussão do papel da empresa na tarefa de fundamentar as suas atividades de forma sustentável. Para Savitz e Weber (2006, p. x-xi),

Sustentabilidade é a arte de fazer negócios em um mundo interdependente; significa conduzir os negócios de maneira a causar o menor impacto e dano sobre as criaturas vivas e não causar exaustão no ambiente natural, mas antes, restaurar e enriquecê-lo. Sustentabilidade também significa operar um negócio reconhecendo a necessidade e interesses de outras partes - tais como, grupos da comunidade, instituições educacionais e religiosas, a força de trabalho, o público - e que este reconhecimento não esgarça, mas ao contrário, reforça a 
rede de relações que mantêm estas diferentes partes unidas. Para isto, a organização deve identificar um espectro largo de partes interessadas a quem a organização deve prestar contas, desenvolvendo um relacionamento aberto com elas e encontrar caminhos para trabalhar com estas partes interessadas gerando benefício mútuo. Neste contexto, a gestão das relações com os stakeholders ganha contorno estratégico. No longo prazo, isso vai criar mais lucro para a companhia e maior prosperidade social, econômica e ambiental para a sociedade.

Segundo Hart e Milstein (2004), a empresa sustentável contribui para o desenvolvimento sustentável ao gerar benefícios econômicos, sociais e ambientais, considerando interconectados os seus interesses de negócios e os interesses do ambiente natural e da sociedade.

As expectativas dos consumidores, a valorização dos produtos que respeitam o ambiente e as ações de responsabilidade social têm influenciado a definição de estratégias comerciais e de marketing, o que pode ocasionar desde pequenas melhorias nas atividades rotineiras até grandes modificações nos produtos e processos, assim como na imagem e reputação da empresa (VILHA e QUADROS, 2007).

Vilha e Quadros (2007) apontam os critérios que devem ser considerados para o desenvolvimento de novos projetos nas empresas, tanto do ponto de vista social, como do ambiental, como mostra o Quadro 3, a seguir.

\begin{tabular}{|l|l|}
\hline Social & Ambiental \\
\hline $\begin{array}{l}\text { Melhoria na reputação e credibilidade } \\
\text { da organização. }\end{array}$ & Apropriação de características ecologicamente corretas. \\
\hline $\begin{array}{l}\text { Envolvimento dos fornecedores em } \\
\text { processos socialmente responsáveis. }\end{array}$ & $\begin{array}{l}\text { Melhorias nos processos produtivos que ultrapassam a } \\
\text { redução de impactos ambientais ou eficiência na produção. }\end{array}$ \\
\hline $\begin{array}{l}\text { Engajamento da empresa nas ações de } \\
\text { pesquisa e de política governamental. }\end{array}$ & $\begin{array}{l}\text { Competência para enfrentar eventuais pressões impostas por } \\
\text { órgáos reguladores, entidades ambientalistas e sociedade de } \\
\text { forma geral. }\end{array}$ \\
\hline $\begin{array}{l}\text { Envolvimento dos empregados nas } \\
\text { ações de responsabilidade social. }\end{array}$ & $\begin{array}{l}\text { Melhoria na credibilidade da instituição no que se refere aos } \\
\text { benefícios ambientais. }\end{array}$ \\
\hline $\begin{array}{l}\text { Melhoria nas condições da } \\
\text { comunidade. }\end{array}$ & $\begin{array}{l}\text { Promoção de ações e campanhas } \\
\text { socialmente responsáveis. }\end{array}$ \\
\hline
\end{tabular}

Quadro 3 - Critérios socioambientais para o desenvolvimento de novos projetos.

Analisando a questão da sustentabilidade e sua influência sobre a competitividade das organizações, sob um ponto de vista microeconômico, Porter e Van der Linde (1995) observaram como as inovações de produto e processo podem servir para melhorar o desempenho ambiental das empresas e, ao mesmo tempo, fazer com que as empresas obtenham benefícios ou vantagens, como redução de custos, aumento da produtividade e exploração de novos mercados, garantindo posições competitivas à frente da concorrência, com os autores concluindo que há uma grande competitividade no cenário internacional, com relação às questões ambientais.

As questões tratadas pelo desenvolvimento sustentável encaixam-se dentre os fatores estruturais e sistêmicos, principalmente, por ser o desenvolvimento sustentável um conceito macroambiental que influencia os fatores empresariais relacionados ao processo decisório da empresa e a sua forma de atuação (REYDON et al., 2007). 
A gestão estratégica para a sustentabilidade é, portanto, o caminho para a competitividade no longo prazo.

\subsection{O setor de aviação e os aspectos de sustentabilidade}

A indústria aeronáutica se caracteriza pelo uso intensivo de tecnologia, mão-de-obra com altíssima qualificação e os desafios e exigências de uma indústria global. Os volumes de produção são baixos, e os custos elevados, caracterizando uma indústria global, por definição. A globalização da indústria se reflete em seus players - fornecedores, clientes, financiadores, órgãos reguladores - cujas relações transcendem fronteiras nacionais.

Segundo estudo de Whitelegg e Cambridge (2004), os impactos sociais, ambientais e econômicos da aviação incluem aqueles gerados pelas aeronaves, pelos aeroportos, infraestrutura de apoio, como os gerados pela cadeia de suprimentos. Os impactos são de diferentes naturezas, incluindo contribuição para o aquecimento global, poluição do ar, geração de ruídos, entre outros. Os impactos diretos causados pela aviação estão sumarizados na Figura 1 (não são considerados os impactos ao longo da cadeia).

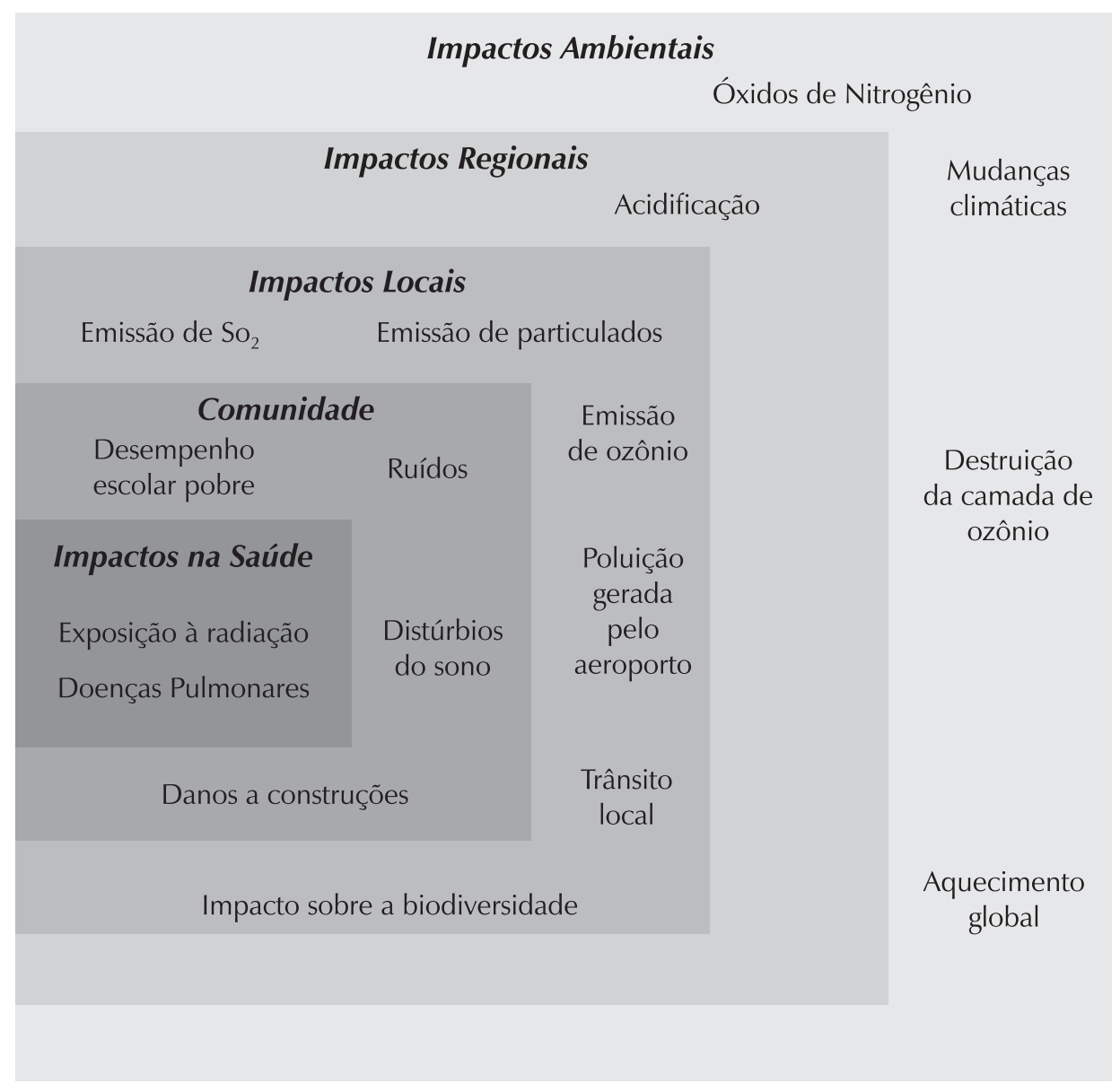

Fonte: Whitelegg e Cambridge (2004, p.15).

Figura 1- Impactos ambientais causados pela aviação.

O impacto ambiental da aviação é alto. Como consome quantidades significativas de combustíveis fósseis, a aviação contribui diretamente para o aumento dos gases do efeito estufa, tendo impacto direto sobre o aquecimento global. Em 2002, as empresas de aviação 
consumiram 205 milhões de toneladas de combustível e geraram mais de meio bilhão de toneladas de gases do efeito estufa. Como são lançados em altas altitudes, os gases emitidos por aviões têm impacto três vezes maior sobre o efeito estufa que gases emitidos em terra. Nos últimos 50 anos, a demanda global por viagens aéreas cresceu $9 \%$ ao ano; estima-se que, atualmente, as companhias aéreas carreguem 1,6 bilhão de pessoas e 30 milhões de toneladas de carga por ano e que nos próximos 20 anos o número de quilômetros voados triplique e o número de aeronaves duplique (SEI, 2007 apud WHITELEGG e CAMBRIDGE, 2004, p 7-9). Outro grande impacto da aviação sobre a saúde humana é a geração de ruídos em áreas próximas aos aeroportos, comprometendo, muitas vezes, o desenvolvimento humano de populações que vivem próximas a aeroportos (WHITELEGG e CAMBRIDGE, 2004, p 7-9).

Ao se considerar que (i) a aviação é um setor que é, em parte, subsidiado pelo governo, ou seja, dependente, em algum grau, de recursos fiscais e, portanto, tem o contribuinte como importante stakeholder; (ii) que seu crescimento nos últimos anos tem sido contínuo; (iii) que os gases do efeito estufa emitidos por vôos internacionais não constam nos inventários nacionais nem fazem parte do Protocolo de Kyoto; e que (iv) as projeções indicam manutenção do crescimento continuado nas demandas por viagens aéreas nos próximos 20 anos, torna-se fundamental analisar a responsabilidade socioambiental das empresas de aviação, o impacto socioambiental do setor como um todo e a necessidade de formulação de políticas públicas adequadas à realidade socioambiental atual e futura (WHITELEGG e CAMBRIDGE, 2004, p 7-9).

\section{Análise do caso}

\subsection{A empresa analisada: Embraer}

Apesar de ter sido fundada em 1969, a partir de uma iniciativa governamental, a Embraer teve, em seu planejamento de longo prazo, a intenção de ser transferida para investidores privados, tendo sempre uma relação próxima dos mercados. Seus primeiros produtos - e, podese dizer, até sua própria criação - visavam suprir a necessidade do Ministério da Aeronáutica de produzir pequenos bimotores de transporte para a Força Aérea, projeto, então, desenvolvido pela equipe do capitão Ozires Silva. Seus primeiros produtos, já na década de 1970, foram: o Bandeirante, um avião para passageiros; uma aeronave para pulverização de lavouras, o Ipanema; e um jato de treinamento, o Xavante. Posteriormente, com o apoio do governo e como resultado da política industrial no período de 1974 a 1988, viu-se um grande crescimento da empresa, que, a partir daí, passou a atuar mais fortemente no mercado internacional (SULL e ESCOBARI, 2004, p. 71-90).

Atualmente, a Embraer opera nos mercados de aviação comercial e executiva, mercado de defesa e governo e aviação agrícola. Tem ações negociadas na Bovespa desde 1996 e, desde 2000, a empresa tem American Depositary Receipts (ADRs) negociadas na bolsa de Nova Iorque. Em 2006, a empresa passou a integrar o Índice de Sustentabilidade Empresarial (ISE) da Bovespa (EMBRAER, 2006).

Em 2006, a Embraer se transformou em uma empresa com capital pulverizado, sem a figura do Grupo de Controle ou do acionista controlador, e obteve o Investment Grade pela Moody's e Standard \& Poor's. No período de 1998 a 2006, sua receita líquida teve o ápice em 2004 (R\$ 10,2 bilhões); em 2006, a receita líquida foi de $\mathrm{R} \$ 8,3$ bilhões. A queda de receita está relacionada a: (i) problemas ocorridos com a montagem de aviões, atrasando a entrega de encomendas e (ii) por ser uma empresa exportadora, a desvalorização do dólar, de cerca de $8 \%$ em 2006, teve impacto direto sobre a receita - 95\% da receita e $85 \%$ dos custos estão 
atrelados ao dólar. O valor de mercado da Embraer vem crescendo desde 2004. Em 2004, sua capitalização de mercado era US\$ 6 bilhões; em 2005, US\$ 7 bilhões e, em 2006, US\$ 7,7 bilhões (EMBRAER, 2006).

\subsection{O processo de internacionalização da Embraer}

O movimento de expansão internacional da Embraer tem seu início, em 1979, quando a empresa obteve uma licença para produzir aviões Piper. Simultaneamente, o governo brasileiro aumentava de $7 \%$ para $50 \%$ as tarifas sobre a importação dos similares estrangeiros do produto, possibilitando um grande sucesso de vendas - mais de mil aviões Piper nos quatro anos seguintes.

O passo seguinte foi a certificação do modelo Bandeirante nos Estados Unidos, França e Reino Unido, o que impulsionou fortemente as exportações para aqueles países. Além disso, novos produtos, como o Brasília (turboélice), o jato AMX e o CBA 123 (substituto do Bandeirante) também fortaleciam a posição da Embraer no mercado externo (SULL e ESCOBARI, 2004, p. 71-90).

Após um período crítico para a empresa, de recessão mundial e grandes mudanças políticas, como a queda do Muro de Berlim, em 1991, após cinco anos, Ozires Silva volta para a empresa, realizando uma preparação para o processo de privatização da Embraer. Com a redução do número de funcionários, mudanças no portfólio de produtos e transferência de dívidas para o governo e novos investimentos por parte deste. Finalmente, em 1994, a empresa foi privatizada (SULL e ESCOBARI, 2004, p. 71-90).

Após sua privatização, a Embraer passou a concentrar esforços em um novo produto, o jato de 50 lugares ERJ 145, próprio para atender ao mercado de jatos regionais, em expansão. Para assegurar presença internacional direta, a Embraer abriu escritórios na Austrália (1997), China (2000), Cingapura (2000) e um novo centro de distribuição em Dallas. Após sucessos consecutivos, a empresa passou novamente a ser lucrativa e seu foco estratégico voltou-se para dentro, na busca por eficiência e melhoria dos processos de gestão. Em 1999, a Embraer passou a ter produtos que concorrem diretamente não apenas com a Bombardier, sua tradicional rival, mas também com Boeing e Airbus (SULL e ESCOBARI, 2004, p. 71-90).

Após a crise aérea, causada pelos atentados de 11 de setembro de 2001, a Embraer sofreu uma série de cancelamentos de encomendas, sendo que os recursos para a construção já estavam comprometidos. Assim, houve impactos importantes para a empresa, como a demissão de 1.800 funcionários (SULL e ESCOBARI, 2004, p. 71-90).

\subsection{A internacionalização da Embraer e os aspectos relacionados à sustentabilidade}

Atualmente, a Embraer tem uma estratégia de internacionalização já consolidada, "ligada à conquista e presença física da empresa nos mercados-alvo internacionais" (EMBRAER, 2006), que tem determinado suas ações em outros países. É importante notar que a internacionalização é um dos quatro direcionadores estratégicos do negócio Embraer, a saber:

- crescimento e perpetuidade: vinculados aos processos de governança corporativa, como a pulverização do capital ocorrida em 2006;

- internacionalização: ligada à conquista e presença física da empresa nos mercadosalvo internacionais;

- participação crescente em mercados estratégicos: relativo à busca do crescimento 
de suas operações por meio do lançamento de produtos e serviços como resultado de análises criteriosas das oportunidades de mercado e retorno dos investidores (elementos básicos da sua estratégia empresarial);

- parcerias industriais: busca de parcerias em escala global (EMBRAER, 2006).

No mesmo Relatório, são apresentados os seguintes valores: ética e respeito à lei (respeito às disposições legais dos países onde atua); satisfação dos clientes; transparência na relação com acionistas (transparência nas práticas de governança corporativa); valorização dos colaboradores (investimento nos funcionários da empresa); compartilhamento de resultados (políticas de remuneração variável; responsabilidade social (ações voltadas à preservação do ambiente, da saúde e da qualidade de vida dos empregados e suas famílias e para o desenvolvimento das comunidades em que se encontra inserida).

Assim, seguindo o propósito deste estudo, é feita uma análise da relação dos aspectos de sustentabilidade com o processo de internacionalização da empresa. Como ponto central da análise deste trabalho, não se pôde verificar que a sustentabilidade esteja explicitada diretamente na sua estratégia de longo prazo. Em seu website, a empresa comunica que suas diretrizes rumo ao desenvolvimento sustentável são:

\footnotetext{
- Promover a conscientização de toda a força de trabalho sobre esta Política, o atendimento à legislação de Meio Ambiente, Segurança e Saúde no trabalho e a prevenção da poluição e dos riscos;

- Coordenar as ações para a melhoria contínua do Meio Ambiente, Segurança e Saúde no trabalho, zelando pela sua permanente adequação aos requisitos das partes interessadas (EMBRAER, 2007).
}

Assim, do ponto de vista deste estudo e de acordo com as informações obtidas em entrevista, destacam-se como grandes temas para a empresa:

\section{a) Sustentabilidade e estratégia:}

- a gestão para sustentabilidade é percebida pela empresa como um caminho natural para a competitividade internacional futura da organização, embora, seja claro para a Embraer, que novos desafios de gestão para a sustentabilidade precisam ser definidos e perseguidos;

- a área de planejamento estratégico monitora o avanço das demandas mundiais por práticas de gestão socioambientalmente mais responsáveis.

\section{b) Questões do ambiente natural:}

- o tratamento das questões socioambientais na Embraer evoluiu da reciclagem de materiais e resíduos para gestão de resíduos, a fim de evitar possíveis passivos ambientais (minimização de riscos). Atualmente a empresa tem um programa de reciclagem que minimiza o envio de resíduos aos aterros. A empresa está desenhando, ainda, como poderia galgar níveis superiores de gestão ambiental;

- um dos fatores motivadores para a evolução da gestão socioambiental apresentado pela empresa é a pressão do mercado externo, tanto do ponto de vista de clientes e reguladores como de credores: há uma intensa preocupação com o impacto da indústria no ambiente natural, especialmente, no caso da Embraer, com a utilização de produtos químicos utilizados na manufatura dos aviões. As pressões são especialmente mais fortes na comunidade européia e credores internacionais;

- na Embraer, a área de meio ambiente está vinculada à vice-presidência financeira e de relações com investidores, sob as quais se encontram as áreas de infra-estrutura, obras e 
serviços. Este aspecto demonstra que os gestores da empresa entendem que o assunto meio ambiente tem impacto sobre a competitividade da organização; e qualidade;

- a Embraer tem um sistema integrado de gestão de meio ambiente, segurança, saúde

- a empresa transfere as práticas de gestão ambientais adotadas no Brasil para seus sítios produtivos no exterior, especialmente na China e nos Estados Unidos, onde a legislação ambiental, muitas vezes, é menos restritiva que a legislação brasileira e as práticas são recomendadas por credores internacionais (como Banco Mundial, por exemplo);

- há dois anos, a empresa introduziu aspectos socioambientais para qualificação da cadeia internacional de fornecedores, ou seja, para se qualificar como fornecedor da Embraer é necessário assegurar práticas ambientais responsáveis (com adequado licenciamento ambiental) e gestão responsável de funcionários (evitando contribuir para organizações que tenham trabalho forçado e/ou escravo).

c) Questões sociais:

- para o caso de ações sociais, as diretrizes são brasileiras, mas as práticas são decididas localmente;

- a empresa coloca como um importante desafio desenvolver a dimensão social em todas as unidades porque identifica esta demanda como crescente.

Assim, de forma geral, a Embraer demonstra preocupação com os impactos das questões socioambientais sobre a sua competitividade nos mercados internacionais. A empresa demonstra uma grande preocupação com certo nível de compliance, de acordo com a regulamentação setorial, fruto das pressões externas para evolução das práticas ambientais da indústria e tem práticas para busca de sustentabilidade expressas em sua estratégia de internacionalização.

\section{Considerações finais}

Quando foi feita a análise do caso e a comparação com os conceitos levantados na revisão da literatura, alguns pontos se destacaram. Primeiramente, a "talvez" inexorável tendência de ênfase na integração dos três componentes do desenvolvimento sustentável - crescimento econômico, eqüidade social e proteção ao meio ambiente -, e a integração entre os aspectos de curto e longo prazo (ELKINGTON apud ALMEIDA, 2006). Principalmente por se tratar de uma indústria de ponta, alta tecnologia e competitividade, a consideração desses aspectos deve tomar corpo de forma a se cristalizar como prática - e necessidade - em um futuro próximo. A estratégia de sustentabilidade pressupõe que as questões sociais, ambientais e econômicas permeiem a formulação estratégica, estejam alinhadas em todos os níveis organizacionais e sejam avaliadas por indicadores de desempenho nessas três dimensões.

Com relação à questão da estratégia, a declaração da visão de uma empresa transmite objetivos estratégicos de longo prazo e como se pretende atingi-los (ALMEIDA, 2003, p.16). As empresas não precisam (e normalmente não o fazem) divulgar todos os seus objetivos estratégicos em sua declaração da visão, mas quando uma organização opta por divulgar sua declaração, geralmente está comunicando ao mercado quais seus grandes desafios estratégicos, aqueles com os quais sua direção estará prioritariamente comprometida. No caso da Embraer (2004), sua visão é: "A Embraer continuará a crescer para ser uma das principais forças globais dos Mercados Aeronáutico e de Defesa, líder nos seus segmentos de atuação, reconhecida pelos níveis de excelência em sua ação empresarial". 
Isso permite derivar a importância de sua atuação global, respaldada pela ação empresarial de qualidade, o que, no futuro (e já no presente) significará a busca de políticas e ações sustentáveis para as organizações.

No caso do setor estudado, conforme pesquisa de Whitelegg e Cambridge (2004), o alto impacto ambiental próprio da indústria deve levá-la a novos caminhos em termos de uso de energias alternativas e redução de impactos ambientais e sociais. Toda a cadeia produtiva deverá estar envolvida, incluindo ainda institutos de pesquisa e órgãos governamentais, sob o risco de morte da própria indústria, com a liquidação dos estoques de capital natural para manutenção dos recursos que sustentam o capital manufaturado, o que poderá levar ambos ao colapso (MERICO, 1996).

Outro ponto a ser destacado é a atuação sustentável em diferentes frentes, principalmente focos importantes como Estados Unidos e China. Em alguns países, existem políticas protecionistas em nome do "desenvolvimento sustentável", o que têm criado barreiras de importação para produtos provenientes de países e empresas que não desenvolvem internamente programas de incentivo à proteção do meio ambiente (PIENIZ, 2001).

Finalmente, as empresas, de modo geral, estão sendo desafiadas a responder às pressões globais por práticas de gestão inovadoras do ponto de vista socioambiental sem, contudo, muitas vezes, terem disponíveis modelos de gestão para a sustentabilidade amplamente divulgados e testados. No caso da indústria aeronáutica, este desafio tem contorno particular: embora os consumidores e o mercado venham exercendo pressão sobre as empresas para que evoluam nesse sentido, há poucos substitutos para os produtos e serviços da indústria aeronáutica. ${ }^{5} \mathrm{~A}$ dependência da sociedade contemporânea da aviação comercial é indiscutível. Portanto, é possível que as forças de mercado (socioambientais) atinjam mais diretamente as empresas de aviação por meio de regulações cada vez mais restritivas, especialmente quando se considera o debate mundial sobre aquecimento global. Tendo em vista este cenário, quanto mais cedo as empresas do setor se posicionarem estrategicamente quanto à sustentabilidade, maiores os ganhos que obterão em competitividade.

\section{Referências bibliográficas}

\author{
ALMEIDA, M. F. L. Sustentabilidade \\ corporativa, inovação tecnológica e \\ planejamento adaptativo: dos princípios à ação. \\ Rio de Janeiro: Ed. da PUC-RJ, 2006.
}

ALMEIDA, M. I. R. de. Manual de planejamento estratégico: desenvolvimento de um plano estratégico com a utilização de planilhas Excel. 2. ed. São Paulo: Atlas, 2003.

AMARAL, S. P.; LA ROVERE, E. L. Indicators to evaluate environmental, social and economic sustainability: a proposal for the Brazilian oil industry. Oil \& Gas Journal, Tulsa, May, 2003, v. 101, p. 30.

ARBIX, G.; SALERNO, M.; DE NEGRI, J. A. A nova competitividade da indústria e o novo empresariado. In: Fórum Nacional 2005. Rio de Janeiro: José Olympio, 2005.

BARTLETT, C.A.; GHOSHAL, S. Transnational management. 2. ed. Boston: McGraw-Hill, 1998.

BENNETT, M.; JAMES P. Environment under the

${ }^{5} \mathrm{~A}$ Bombardier oferecerá aos seus clientes a possibilidade de reduzir sua pegada ecológica pelo programa de compensação de créditos de carbono como compensação pelo impacto das emissões e do combustível utilizado. 
spotlight: current practice and future trends in environment-related performance measurement for business. London: ACCA, 1998.

DUNNING, J. H. Multinational enterprises and the global economy. London: Addison-Wesley, 1999.

EMBRAER. Relatório anual 2006. Disponível em: <http://www.embraer.com.br>. Acesso em: 20 out. 2007.

FUNDAÇÃO DOM CABRAL. Pesquisa sobre a internacionalização da empresa brasileira: sumário executivo, jul. 2002.

HARRIS, J. et al. (Orgs.). A survey of sustainable development: social and economic dimensions. Washington: Island, 2001.

HUNT, C.B.; AUSTER, E. R. Proactive environmental management: avoiding the toxic trap. Sloan Management Review, Winter 1990.

MATTAR, F.N. Pesquisa de marketing. São Paulo: Atlas, 1996.

MERICO, L. F. K. Introdução à economia ecológica. Blumenau: Ed. da FURB, 1996.

MORAN, R.T.; HARRIS, P.R.; STRIPP, W.G. Desenvolvendo organizações globais. Tradução de Cristina Bazán. São Paulo: Futura, 1996.

PIENIZ, L.P. A identificação dos custos ambientais: o caso do curtume Monbelli Ltda.Tapera/RS. In: CONGRESSO BRASILEIRO DE CUSTOS: A CONTROLADORIA NO NOVO CONTEXTO ORGANIZACIONAL, 8., 2001.

São Leopoldo. Anais... São Leopoldo: Ed. da Universidade do Vale do Rio dos Sinos, 2001. cd-rom.

PORTER, M.; LINDE, C .V. D. Green and competitive: ending the stalemate. Harvard

Business Review, v. 73, n. 5, p. 120-134, Sept./ Oct., 1995.

PORTER, Michael E.; VAN DER LINDE, C.

Toward a new conception of the environmentcompetitiveness relationship. Journal of

Economics Perspectives, Boston, v. 9, n. 4, p. 97-118, Fall 1995.
REYDON, B. P. et al. Texto para discussão. Campinas: IE/UNICAMP, n. 125, jun. 2007.

SAVITZ, A. W.; WEBER, K. The triple bottom line: how today's best run companies are achieving economic, social and environmental success - and how you can too. San Francisco: John Wiley \& Sons, 2006.

SCHOEMAKER, P.J.H.; SCHOEMAKER, J.A. Estimating enviromental lyability: quantifying the unknown. California Management Review, Spring, v.l. 37, n. 3, 1995.

SEI. Disponível em: <http:// www.sei.se>. Acesso em: 13 out. 2007.

SELLTIZ, C. et al. Métodos de pesquisa nas relações sociais. 2. ed. Tradução de Dante Moreira Leite. São Paulo: EPU, 1974. 687 p.

SILVA, M. L. A inserção internacional das grandes empresas nacionais. In: LAPLANE, M.; COUTINHO, L.; HIRATUKA, C. (Orgs.). Internacionalização e desenvolvimento da indústria no Brasil. São Paulo: Ed. UNESP, 2003.

SULL, D.N., ESCOBARI, M.E. Sucesso made in Brasil: os segredos das empresas brasileiras que dão certo. Rio de Janeiro: Ed. Campus, 2004, 256 p.

TRIVIÑOS, A. N. S. Introdução à pesquisa em Ciências Sociais: a pesquisa qualitativa em educação. São Paulo: Atlas, 1987.

VILHA, A.M.; QUADROS, R. Development of sustainable products: analysis of the implications on the management of technological innovation projects of a brazilian company. In: ENANPAD, 31., Rio de Janeiro. Anais... Rio de Janeiro, 2007. cd-rom.

WHITELEGG, J.; CAMBRIDGE, H. Aviation and sustainability: a policy paper. Stockholm Environment Institute, July 2004. Disponível em: <http://www.sei.se>. Acesso em: 13 out. 2007.

YIN, R.K. Estudo de caso: planejamento e métodos. Tradução de Daniel Grassi. Porto Alegre: Bookman, 2001. 